\title{
Adult Epithelioid Sarcoma
}

National Cancer Institute

\section{Source}

National Cancer Institute. Adult Epithelioid Sarcoma. NCI Thesaurus. Code C7944.

An epithelioid sarcoma occurring in adults. 